Sir,

\section{Exercise-induced diplopia}

Whereas exercise-induced visual loss is usually due to demyelinating optic neuropathy, the much less common entity of exercise-induced double vision is usually due to intracranial glioma. We report an unusual case of exercise-induced double vision highlighting the importance of neuroimaging in such cases.

\section{Case report}

A 14-year-old male presented with an 18 months history of double vision only while running. His right eye was noted to turn inwards. The double vision resolved after 3-4 min rest. It did not occur with hot baths or when he was tired. He denied any other neurological symptoms.

There was a small right esotropia (18 $\Delta$ for distance), with bifoveal fixation and $60 \mathrm{~s}$ of arc stereoacuity (TNO test) but a positive four-prism dioptre test with the right eye. Extraocular movements and saccades were normal on clinical examination but Hess chart showed mild limitation of abduction of the left eye. After exercise there was double vision with a moderate right esotropia $(40 \Delta)$. Extraocular movements and saccades were still normal.

The double vision resolved and the ocular alignment returned to the preexercise state after $5 \mathrm{~min}$ rest.

Neurological examination was normal.

Magnetic resonance imaging (MRI) showed an extensive T2 high-signal lesion involving both sides of the pons extending into the medulla with mild swelling but no contrast enhancement, consistent with a brainstem glioma

(Figure 1).

Cerebrospinal fluid examination including cytology was normal. Initially following radiotherapy (54 Gy in 30 doses over 6 weeks) there was clinical deterioration with diplopia at rest, increased esotropia and mild slowing of abducting saccades of the left eye. Subsequently there was gradual resolution of symptoms. One year after treatment, the patient was asymptomatic, even on exercise. He had a well-controlled esophoria and the brain stem lesion had regressed on MRI.

\section{Comment}

Chronic-isolated sixth nerve palsy ${ }^{1}$ and acute divergence weakness esotropia ${ }^{2,3}$ are recognised presentations of

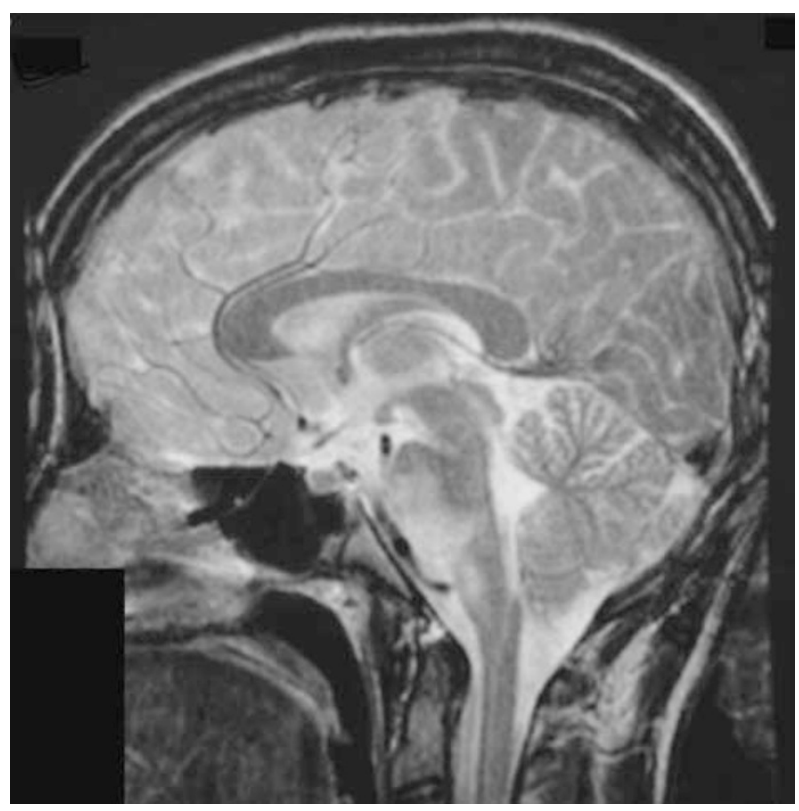

Figure 1 MRI demonstrating brain stem glioma.

brainstem glioma. Although clinically there was no limitation of abduction or slowing of abduction saccades, even after exercise, the Hess chart indicated mild left lateral rectus palsy. This was supported by the development of slowed abduction saccades following radiotherapy.

Among three previously reported cases of exerciseinduced diplopia, two had cerebral or cerebellar astrocytoma and no cause was identified in the third. ${ }^{4-6}$ This contrasts with exercise-induced visual loss (Uhthoff's phenomenon) that is usually due to demyelinative optic neuropathy. Exercise-induced double vision is uncommon but is usually due to intracranial glioma.

\section{References}

1 Galetta S, Lawton Smith J. Chronic isolated sixth nerve palsies. Arch Neurol 1989; 46: 70-82.

2 Schanzer B, Bordaberry M, Jeffery A, McNeil D, Phillips P. The child with divergence paresis. Surv Ophthalmol 1998; 42: 571-576.

3 Brown SM, Iacuone JJ. Intact sensory fusion in a child with divergence paresis caused by a pontine glioma. $A m \mathrm{~J}$ Ophthalmol 1999; 128: 528-530.

4 Astle WF, Miller SJ. Bilateral fluctuating trochlear nerve palsy secondary to cerbellar astrocyoma. Can J Ophthalmol 1994; 29: 34-38.

5 Shinton RA, Jamieson DG. Exercise induced diplopia as a presentation of midline cerebral tumour. J Neurol Neurosurg Psychiatry 1989; 52: 916-917.

6 Oesterle CS. Exercise induced esotropia. J Pediatr Ophthalmol Strabismus 1989; 26: 150-151. 
S Kashani, S Madil, C Tan and P Riordan-Eva

Department of Ophthalmology, King's College Hospital NHS Trust, Denmark Hill, London SE5 9RS, UK

Correspondence: S Kashani, No. 30 Woolcombes court, Princes Riverside Road, Rotherhithe, London SE16 5RQ, UK

Tel: + 447711716511 ;

Fax: + 442073463738 .

E-mail: shahdoc@hotmail.com

Eye (2006) 20, 628-629. doi:10.1038/sj.eye.6701950; published online 10 June 2005

Sir,

Photodynamic therapy (PDT) using verteporfin for juxtafoveal choroidal neovascularisation $(\mathrm{CNV})$ in angioid streaks (AS) associated with pseudoxanthoma elasticum: 40 months results

\section{Case report}

A 55-year-old engineer with pseudoxanthoma elasticum developed angioid streaks (AS)-associated classic justafoveal choroidal neovascularisation $(\mathrm{CNV})$ in his right eye (Figure 1a). His BCVA was 6/24 in his right eye (55 letters on ETDRS chart including added 15 letters, contrast sensitivity:1.05) and 6/60 in his left eye due to disciform macular scar. Photodynamic therapy (PDT) with Verteporfin as per the TAP criteria ${ }^{1}$ was performed. No adverse effect was noted during or after treatment.

He underwent seven further PDT treatments over the following 40 months. At the most recent visit, his BCVA remains stable at 58 letters and contrast sensitivity at 1.45 (Figure 1b). Details are summarised in Table 1, Figure $2 \mathrm{a}$ and $\mathrm{b}$.

\section{Comment}

AS are associated with a diverse group of conditions including pseudoxanthoma elasticum (PXE). Eyes with
PXE-related AS may be complicated by $\mathrm{CNV}$ and subsequent serous or haemorrhagic retinal detachment. ${ }^{2}$ $\mathrm{CNV}$ accounts for the majority of severe visual impairment
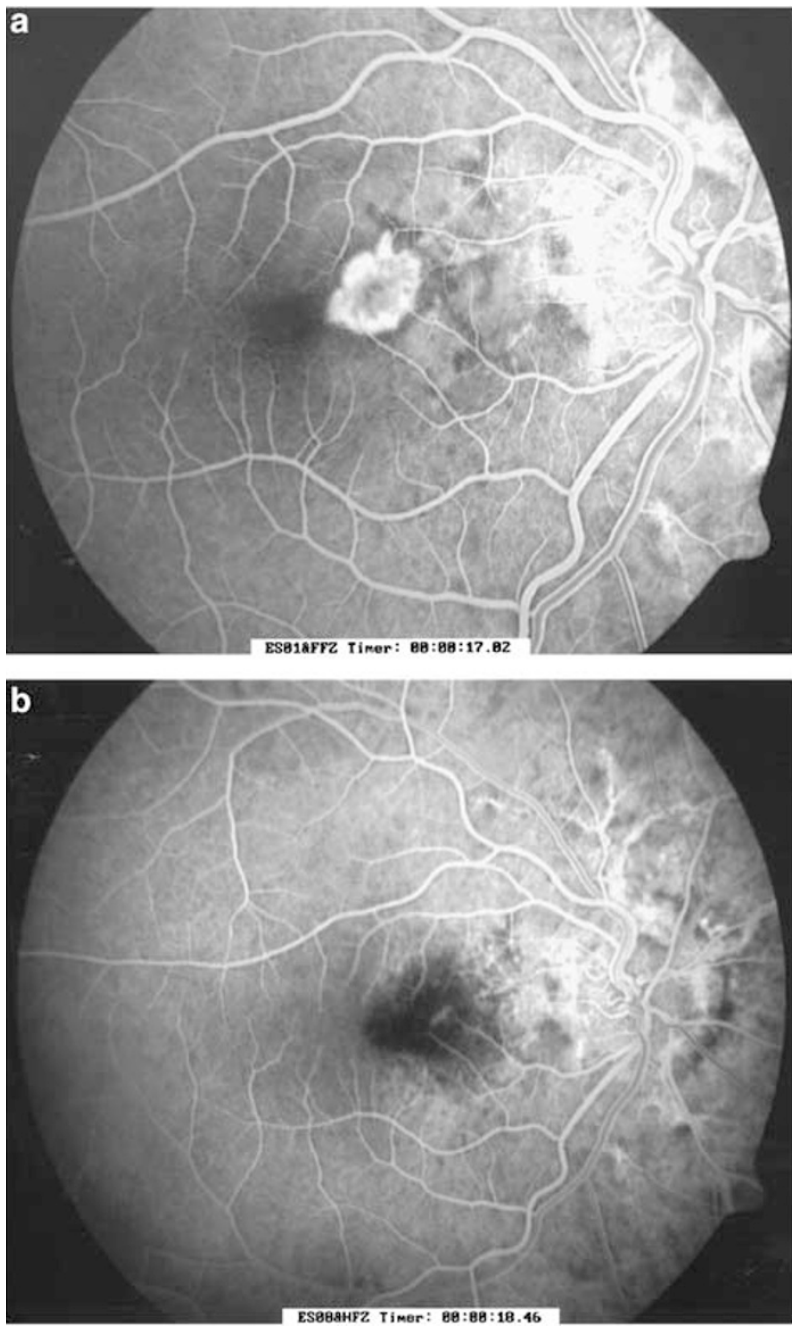

Figure 1 (a) Pre-PDT: early phase of fundus fluorescein angiogram (OD) showing classic juxtafoveal CNV associated with AS. (b) Post-PDT: early phase of fundus fluorescein angiogram of the same eye showing absence of leakage 2 weeks after initial PDT treatment.

Table 1 Summary of visual acuity, contrast sensitivity, number of PDT treatments, and size of treated area over 40 months

\begin{tabular}{|c|c|c|c|c|c|c|c|c|c|c|c|c|c|c|}
\hline Follow-up (months) & 0 & 3 & 6 & 9 & 12 & 15 & 18 & 21 & 24 & 27 & 30 & 33 & 36 & 40 \\
\hline $\begin{array}{l}\text { VA: number of letters read on ETDRS } \\
\text { chart }(\text { at } 2 \mathrm{~m})\end{array}$ & 55 & 59 & 43 & 56 & 56 & 62 & 64 & 64 & 55 & 58 & 58 & 57 & 63 & 58 \\
\hline Contrast sensitivity & 1.05 & 1.15 & 0.90 & 0.95 & 0.95 & 1.40 & 1.40 & 1.50 & 1.50 & 1.50 & 1.50 & 1.50 & 1.45 & 1.45 \\
\hline PDT treatment $(Y-Y e s, N-N o)$ & Y & Y & Y & $\mathrm{Y}$ & $\mathrm{N}$ & $\mathrm{Y}$ & $\mathrm{N}$ & Y & $\mathrm{Y}$ & $\mathrm{N}$ & Y & $\mathrm{N}$ & $\mathrm{N}$ & $\mathrm{N}$ \\
\hline $\begin{array}{l}\text { Greatest Linear Diameter } \\
-G L D(\mu m)\end{array}$ & 2400 & 2400 & 2650 & 2300 & - & 2500 & - & 3100 & 3200 & - & 3200 & - & - & - \\
\hline
\end{tabular}

